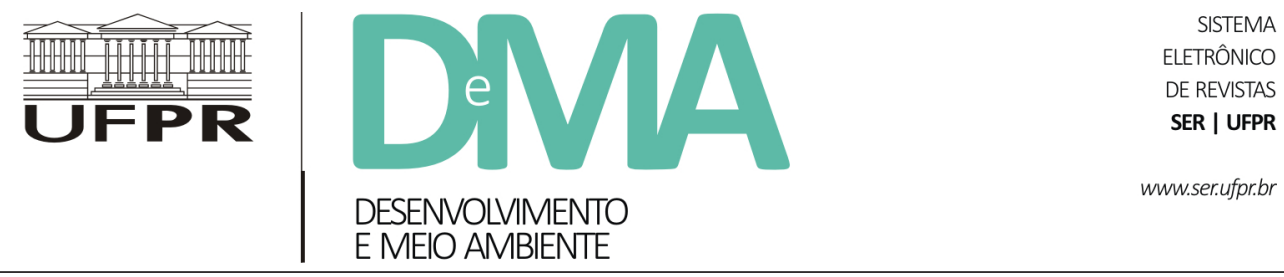

\title{
Motivações socioeconômicas para a conservação e exploração sustentável do bioma Caatinga
}

\section{Socioeconomic Motivations for Conservation and Sustainable Use of the Caatinga Biome}

Josemir Moura MAIA ${ }^{1 *}$, Valéria Fernandes de Oliveira SOUSA ${ }^{2}$, Emannuella Hayanna Alves de LIRA ${ }^{1}$, Amanda Micheline Amador de LUCENA ${ }^{3}$

${ }^{1}$ Programa de Pós-Graduação em Ciências Agrárias, Universidade Estadual da Paraíba (UEPB), Campina Grande, PB, Brasil.

${ }^{2}$ Universidade Federal de Campina Grande (UFCG), Pombal, PB, Brasil.

${ }^{3}$ Saberes Assessoria Educacional, Campina Grande, PB, Brasil.

*E-mail de contato: jmouram@gmail.com

Ensaio recebido em 13 de novembro de 2016, versão final aceita em 23 de maio de 2017.

RESUMO: $\quad$ Nesse trabalho propõe-se contribuir com as discussões sobre a exploração sustentável da Caatinga através de uma atualização bibliográfica sobre o tema, destacando a importância desse bioma, suas potencialidades e a necessidade de sua preservação e conservação. Foram abordadas a importância socioeconômica do bioma, as estratégias de subsistência e geração de renda (como o extrativismo e bioprodutos de valor econômico), as políticas públicas e ameaças, além de avaliar o seu uso sustentável. Com base no exposto, compreende-se que o manejo sustentável é uma possibilidade real, tecnicamente comprovada. Faz-se necessário um intenso processo de conscientização e capacitação de todos os atores envolvidos por meio da formulação de políticas públicas, que priorizem a realidade ambiental e socioeconômica do bioma, da geração, sistematização e disseminação de informações, da construção de uma matriz de incentivos adaptados à realidade local e do fortalecimento institucional, como forma de garantir a sobrevivência do ecossistema.

Palavras-chave: bioma brasileiro; extrativismo sustentável; semiárido.

ABSTRACT: This paper aims to contribute with the discussions about the sustainable exploitation of Caatinga through an updated review of such topic. The research highlights the importance of this biome, thus, proposing its potential, and also the need for its preservation and conservation. This study, more specifically, exposes the socio-economic importance of the biome, on subsistence and income generation strategies, discussing the extraction and bio-products of economic value, public policies and threats, and evaluation of its sustainable use. Thus, considering this discussion it is understood that sustainable management is a real possibility and technically proven. It is necessary an intense process of awareness and training of all involved actors through 
formulation of public policies that prioritize the environmental and socioeconomic reality of biome. This can be done through the generation, systematization and dissemination of information, construction of incentives adapted to the local reality and institutional strengthening as a way to guarantee the survival of the ecosystem.

Keywords: Brazilian biome; sustainable harvesting; semiarid.

\section{Introdução}

A Caatinga, bioma predominante do Semiárido brasileiro, cobre cerca de $80 \%$ de sua área geográfica, ocupando uma área de $826.411,23 \mathrm{~km}^{2}$ (Ibama, 2009). O termo Caatinga foi originado do tupi-guarani e é tradicionalmente interpretado como mata (caa) branca (tinga). A Caatinga também é conhecida como sertão, agreste, cariri, seridó, carrasco - denominações populares para as diferentes formações vegetais do bioma (Araújo Filho, 2013). Esse domínio vegetacional configura-se numa região diversificada de paisagens e tipos vegetacionais, composta por um mosaico de arbustos espinhosos, florestas sazonalmente secas e clima semiárido que cobre totalmente o Ceará e parte dos estados do Rio Grande do Norte, Paraíba, Pernambuco, Piauí, Alagoas, Sergipe, Bahia e uma faixa seguindo o rio São Francisco em Minas Gerais (Prado, 2003). Toda essa diversidade é resultada de variações geomorfológicas, climáticas, topográficas, e pela ação antrópica, que influenciam na distribuição e diversidade das espécies vegetais (Araújo Filho, 2013).

A vegetação da Caatinga é composta, principalmente por plantas xerófitas, formada por espécies que desenvolveram mecanismos para sobreviver em ambiente com poucas chuvas e baixa umidade. No bioma são comuns árvores baixas e arbustos, muitas vezes espinhosos. Nos cactos, por exemplo, estes espinhos são folhas modificadas que diminuem a perda de água pela transpiração (Moraes, 2016). As espécies lenhosas expõem mecanismos de resistên- cia à seca, sendo perenifólias e apresentando folhas pequenas ou folíolos, céreos ou rugosos, superfície foliar ondulada, com os estômatos localizados na parte côncava, espinhos ou acúleos, caules com vasos lenhosos curtos e de pequeno diâmetro, com paredes espessas, sistema radicular profundo e extenso (Araújo Filho, 2013). Essas estratégias morfofisiológicas expressam erroneamente que a vegetação está morta, por esta se apresentar sem folhas, só como caules e troncos secos e retorcidos (Moraes, 2016). Na realidade essas plantas adaptadas ao clima Semiárido permanecem vivas, utilizando de seus mecanismos (espinhos, raízes bem desenvolvidas, armazenamento de água, caducifólia entre outros) para sobreviver às adversidades do ambiente.

Toda essa diversidade é representada por mais de duas mil espécies, destacando-se aproximadamente 130 espécies endêmicas (Queiroz, 2011); por este motivo, é considerado um bioma rico em recursos genéticos quando comparada a outras regiões semiáridas no mundo (Calixto-Junior \& Drumond, 2014). No entanto, a Caatinga é, provavelmente, o menos estudado em relação à flora e à fauna e um dos que têm mais sofrido degradação nos últimos 400 anos devido ao uso desordenado e predatório (Bezerra et al., 2014). Também é considerado como o terceiro bioma mais degradado do Brasil, com $51 \%$ de área alterada pela ação humana (Alvarez \&Oliveira, 2013). Além disso, muitas das áreas protegidas por lei ainda estão suscetíveis a ameaças, o que tem contribuído para a perda gradativa da 
biodiversidade (Silva et al., 2013). Este fato remete a uma reflexão sobre o manejo sustentável dos recursos naturais da Caatinga, pois, segundo Paupitz (2010), este manejo é uma possibilidade real, que poderia contribuir para o desenvolvimento econômico e social da região Nordeste. Assim, propõe-se nesse estudo contribuir com as discussões sobre o tema, através de uma atualização bibliográfica sobre aspectos socioeconômicos da Caatinga, destacando a importância desse bioma, evidenciando suas potencialidades e a necessidade de sua preservação e conservação.

\section{Importância socioeconômica do bioma Caatinga}

Dentre os biomas brasileiros, a Caatinga é, provavelmente, o menos conhecido pela Botânica e o mais desvalorizado, dada a reduzida exploração sustentável dos recursos naturais e a elevada proporção de terras desmatadas para pecuária. Esta situação é decorrente da crença de que a Caatinga é o resultado da modificação de outra formação vegetal, estando associada a uma diversidade muito baixa de plantas, sem espécies endêmicas e altamente modificada pelas ações antrópicas (Giulietti et al., 2010). Contudo, estudos têm desafiado esse ponto de vista e demonstrado a importância da Caatinga para a conservação da biodiversidade brasileira (Leal et al., 2003a; Viana, 2011). Araújo Filho (2013) descreve oito formações vegetais no bioma Caatinga: (1) arbórea; (2) arborescente com substrato arbustivo aberto; (3) arborescente arbustiva fechada; (4) arborescente aberta com substrato de bromeliáceas e cactáceas; (5) arbustiva densa; (6) arbustiva aberta típica dos solos rasos com aflo- ramentos rochosos; (7) assavanada formada pelo seridó e tabuleiros sertanejos; e (8) assavanada com afloramentos rochosos.

Como discutido por Giulietti et al. (2010), ainda que a Caatinga esteja severamente alterada, ela contém uma grande variedade de tipos vegetacionais, e também remanescentes de vegetação ainda bem preservados, incluindo um número expressivo de táxons raros e endêmicos. Mas, como indica a Unesco (2012), não é possível ter hoje uma lista completa da flora existente no bioma Caatinga. $\mathrm{O}$ Centro Nordestino de Informação sobre Plantas (CNIP) apresenta na sua listagem 8.760 espécies, com 2/3 dessa lista já revisada. Gamarra-Rojas \& Sampaio (2002) apresentaram uma lista com 1.102 espécies catalogadas na Caatinga. Giulietti e colaboradores (2004) também apresentaram uma lista das espécies endêmicas, relatando 318 espécies distribuídas em 42 famílias. Destas, as famílias de Leguminosae (80 espécies), Cactaceae (41 espécies), Euphorbiaceae (17 espécies), Malvaceae (15 espécies) e Bromeliaceae (14 espécies) se destacam como as mais importantes. Segundo os mesmos autores, considerando somente as plantas lenhosas e suculentas, por exemplo, existem 18 gêneros e 318 espécies endêmicas (34\% das espécies descritas), distribuídos em 42 famílias (Sampaio et al., 2002). Sendo que, esses valores sobre a biodiversidade da Caatinga são muito mais altos que os publicados por Leal et al. (2005) e são tão ou mais densos que aqueles registrados em outras florestas secas do mundo (Leal et al., 2003a).

É perceptível a existência de divergências na literatura sobre a quantidade de espécies pertencentes a esse bioma. O número real de espécies na Caatinga é, provavelmente, ainda maior do que os relatos, uma vez que, até $2005,41 \%$ da região nunca 
havia sido investigada e $80 \%$ permanece subamostrada (Silva et al., 2004; Tabarelli \& Vicente, 2004; Leal et al., 2005). Nesse âmbito, os dados de levantamento florístico nordestino precisam de constante atualização. No entanto, embora os inventários encontrados ainda estejam incompletos, o nível de endemismo também é bastante alto para as espécies vegetais. Adicionalmente, é notória a importância e o potencial econômico que esse bioma apresenta, dada a sua imensa diversidade florística. Sampaio et al. (2006), citados por Queiroz (2011), descreveram que neste bioma as oito formações vegetais distintas da Caatinga, apresentadas por Araújo Filho (2013), são constituídas por plantas produtoras de cera, óleos e taninos, forrageiras, frutíferas, apícolas, ornamentais, produtoras de fibras, medicinais e madeireiras, valendo salientar que algumas das espécies podem apresentar usos múltiplos.

No entanto, a Caatinga ainda está por ser explorada em suas maiores potencialidades, representadas pela sua extraordinária biodiversidade vegetal e sua coleção ainda desconhecida de espécies para uso medicinal, agentes praguicidas, provedores de genes indutores de tolerância aos estresses hídrico e salino, resistência à acidez do solo e a doenças, além de matérias primas para indústria química, alimentar, cosmética e farmacêutica, incluindo plantas produtoras de óleos essenciais (Guimarães Filho, 2012). Dentre as plantas de maior valor socioeconômico, as lenhosas, por serem caducifólias no período seco, adicionam ao solo cerca de quatro toneladas de matéria seca em folhas e galhos, contribuindo com a reciclagem de nutrientes; participando da dieta de bovinos, caprinos e ovinos; e respondendo por $30 \%$ do consumo energético da região nordestina na forma de lenha (Araújo Filho, 2013). Nos Sertões, a lenha satisfaz a mais de 70\% da demanda energética, sendo necessários 78 estéreos para atender a uma residência média a cada ano. Por outro lado, a taxa anual de incremento da produção de madeira na Caatinga é de 5,0 estéreos por hectare (Araújo Filho, 2013).

A atividade pecuarista segue o modelo de exploração misto, com cerca de $90 \%$ das propriedades criando bovinos, caprinos, abelhas, aves e ovinos - produzindo simultaneamente carne, ovos, mel, gordura, couros e peles. O regime de criação é predominantemente extensivo, baseado em condições de sobre pastejo, constituindo a vegetação da Caatinga a principal ou, em muitos casos, a única fonte de alimento para os rebanhos (Araújo Filho, 2013). No entanto, a utilização inadequada dos recursos da Caatinga, como a exploração animal e o extrativismo insustentável, pode levar ao desaparecimento de algumas espécies e à consequente perda da biodiversidade (Embrapa, 2007).

A valorização dos produtos locais é, no contexto da globalização, o grande instrumento estratégico para alcançar os objetivos principais de preservar os recursos da Caatinga e assegurar, ao mesmo tempo, o bem estar das populações que nela vivem e dela dependem (Guimarães Filho, 2012). Produtos diferenciados, a partir da incorporação de uma identidade territorial e cultural, constituem uma alternativa de grande potencial no semiárido. É simplesmente uma questão de um pouco mais de esforço em reconhecer os conhecimentos locais, associando-os, ao conhecimento científico necessário à plena expressão do potencial do bioma. A complementação do processo de valorização dos produtos locais com sua identidade territorial e cultural deve se dar com a implantação de normas que definam e orientem a certificação diferenciada desses produtos (como, por exemplo, o doce de 
palma), requisito básico para o reconhecimento e proteção de produtos cujas qualidades ou características se devam exclusiva ou essencialmente ao meio geográfico, incluídos fatores naturais (solo, clima) e humanos (tradição, cultura). Embora os primeiros passos já estejam sendo dados, como no caso de cooperativas de pequenos produtores que são instaladas em comunidades agrícolas no semiárido, estamos ainda muito atrasados nesse processo (Guimarães Filho, 2012). Esse atraso se deve ao fato de que ainda o processo de valorização dos produtos, e, consequentemente, as cooperativas de produção, o beneficiamento e a comercialização em larga escala são incipientes.

\section{Subsistência e geração de renda na Caatinga}

O Semiárido brasileiro é caracterizado por uma precipitação abaixo de $800 \mathrm{~mm}$ por ano, grande taxa de evaporação e elevado risco de seca. Tem uma extensão aproximada de um milhão de quilômetros quadrados, incluindo 1.133 municípios em nove estados, onde se insere o bioma Caatinga (Queiroz, 2011). A utilização desse bioma ainda se fundamenta em processos meramente extrativistas para obtenção de produtos de origens pastoril, agrícola e madeireiro. Grande parte da população que reside na Caatinga explora sua biodiversidade para sobreviver, obtendo alimentação, remédios, forragem para os mais variados tipos de rebanhos, madeira para construções, entre outros (Loiola et al., 2012). Embora a biodiversidade da Caatinga seja importante para a soberania alimentar e subsistência da população nativa, ela não é a única fonte de subsistência. A base da economia da região é a agropecuária de sequeiro e, em algumas áreas, irrigada. Contudo, nas áreas de sequeiro, os riscos de colheita são grandes e aumentam nos períodos de seca. Já nas áreas irrigáveis, há o risco de salinização, embora sejam crescentes a produção de olerícolas e da fruticultura de manga, uva, banana e coco.

No contexto econômico, a comercialização de produtos dessa região vem se expandindo e conquistando novos mercados. A comercialização dos frutos do umbuzeiro (Spondias tuberosa Arr. Cam.), coletados por famílias de pequenos produtores ou de assalariados agrícolas, é uma atividade crescente em algumas regiões do Nordeste, exceto em Alagoas e Maranhão. A carnaúba (Copernicia prunifera (Mill.) H.E. Moore), importante na produção de cera, concentra-se nos estados do Ceará e Piauí, responsáveis por 80 a $90 \%$ da produção brasileira, no entanto, ainda é pouco expressiva quando comparada à produção comercial. Já o ouricuri ou licuri (Syagrus coronata (Mart.) Becc.), por ser uma palmeira totalmente aproveitável, vem sendo amplamente explorada desde os tempos coloniais (Drumond et al., 2000).

Ainda, diversos produtos madeireiros e não madeireiros são obtidos extrativamente da vegetação da Caatinga. Além da lenha, seu produto economicamente mais importante, a vegetação lenhosa da Caatinga fornece também postes e varas para confecção de cerca, forragem, produtos medicinais e é uma importante área para a apicultura (Araújo Fi1ho, 2013). Mas infelizmente, a exploração agrícola, com práticas de agricultura itinerante (onde consta o desmatamento e a queimada desordenados), tem modificado tanto o estrato herbáceo como o arbustivo-arbóreo. A intensificação do uso do solo, bem como seu uso além da capacidade natural de rege- 
neração dos ecossistemas, vem causando na região da Caatinga vultosas perdas na biodiversidade da fauna e da flora, erosão do solo, sedimentação dos reservatórios e dos rios, com consequente declínio da atividade econômica e da qualidade de vida da população (Araújo Filho, 2013). A isso, soma-se a pecuária que, segundo Drumond et al. (2000), explora de 8 a 13 ha/bovino e de 1 a 1,5 ha/caprino, bem como a formação de pastos, principalmente de capim buffel e gramínea exóticas. Esse superpastoreio tem modificado drasticamente a composição florística do estrato herbáceo nesse bioma.

Assim, percebe-se nas observações supracitadas que, na Caatinga, predominam sistemas de produção mistos, caracterizados como sistema de produção agrossilvipastoril ou silvipastoril, ambos carecendo de estratégias de sustentabilidade em seus índices produtivos. Isso se dá em razão, principalmente, da falta de integração entre os seus componentes agrícola, pecuário e florestal, e por utilizar, em sua maioria, tecnologias extrativistas e predatórias (Araújo Filho, 2013). As consequências desse modelo extrativista predatório se fazem sentir principalmente nos recursos naturais renováveis da Caatinga. Assim, desde o ano 2000, já foram observadas perdas irrecuperáveis da diversidade florística e faunística, além da aceleração do processo de erosão e declínio da fertilidade do solo e da qualidade da água pela sedimentação (Drumond et al., 2000). Essas perdas estão associadas ao assoreamento de nascentes e rios além da redução da capacidade produtiva dos solos causada por queimadas frequentes. Como consequência, a perda na diversidade microbiológica e faunística, por morte e/ou ação migratória, causa desequilíbrio na teia alimentar e prejuízos na atividade de polinização, reduzindo ainda mais a produtividade de frutos e biomassa vegetativa da flora.

\section{Principais bioprodutos extraídos de espécies do bioma Caatinga e perspectivas para o desenvolvimento do extrativismo sustentável dessas espécies}

Na Caatinga, existe um grande número de plantas e de animais utilizados pelo sertanejo, para a produção de alimentos, remédios, forrageiras e fontes de madeira. Muitas das flores desse bioma fornecem néctar e pólen para as abelhas, a partir dos quais elas fabricam o mel. Além disso, algumas plantas (ou produtos) que podem ser comercializados servindo como fonte de renda para o sertanejo são: a oiticica (Licania rígida Benth) e a faveleira (Cnidoscolus quercifolius Pohl) (óleo vegetal), a carnaúba (Copernicia prunifera (Miller) H.E. Moore) (cera e palha) e o caroá (Neoglasiovia variegata(Arr. Cam.) Mez.) (fibras), além das plantas usadas na montagem de arranjos em vasos e na decoração de praças e jardins, como os caroás (Neoglasiovia variegata (Arr. Cam.) Mez.), macambiras (Bromelia laciniosa Mart. ex. Schult.f.) e cactáeas em geral (Embrapa, 2007).

Uma das alternativas para uma exploração sustentável desse bioma é o uso racional de seus bioprodutos. Uma opção promissora é o uso da flora para fins farmacológicos em diversas patologias, visto que vem crescendo nos últimos 30 anos a aprovação de novas drogas para consumo humano, com destaque para os produtos naturais e suas estruturas químicas (Newman \& Cragg, 2012). A diversidade de espécies da Caatinga que já são utilizadas na fitoterapia na forma de chás, garrafadas, lambedores, xaropes, entre outros, é bastante vasta 
e vendida como folhas, cascas, raízes e frutos nas feiras e ruas das cidades. Como exemplo, pode-se citar a aroeira (Astronium fraxinifolium Schott), indicada no combate a problemas do aparelho respiratório, anti-inflamatório, cicatrizante e adistringente; angico (Anadenanthera sp.), no tratamento de doenças do aparelho respiratório; catingueira (Caesalpinia pyramidalisTul.), empregada em problemas gastrointestinais, problemas do aparelho respiratório e geniturinário; araticum (Annona montana Macfad.), antidiarreico; quatro-patacas (Allamanda catártica L.), catártica; pau-ferro ( $\mathrm{Ca}$ esalpinia leiostachya (Benth.) Ducke), antiasmática e anticéptica; catingueira (Caesalpinia pyramidalis Tul.), antidiarréica; velame (Croton heliotropiifolius Kunth.) e marmeleiro (Croton sonderianus Muell. Arg.), antifebris; sabiá (Mimosa caesalpiniifolia Benth.), peitoral; juazeiro (Ziziphus joazeiro Mart.), estomacal; jericó (Selaginella convoluta (Arn.) Spring), diurético; entre outras (Silva \& Freire, 2010; Marinho et al., 2011).

O pau d'arco (Tabebuia sp.) foi uma das espécies que, na década de 1960, foi amplamente despojado de sua casca, a qual era tida como curativa de câncer. Esta prática levou à morte de vários exemplares desta espécie, uma vez que tal operação implica na remoção do tecido cambial. Outrossim, Queiroz (2011) afirmou que, no bioma Caatinga, as plantas medicinais representam um grupo muito significativo, mas não têm sido objeto de estudo no que tange aos recursos genéticos de modo mais sistemático.

Outro mercado promissor onde a Caatinga se destaca é o de biocombustíveis, pois, além de apresentar uma grande variedade de plantas com potencial para esse mercado, este bioma também possui um clima favorável à produção de diversas culturas oleaginosas como: a mamona (Ricinus communi sL.), o pinhão manso (Jatropha curcasL.), o girassol (Helianthus annuusL.), o dendê (Elaeis guineenses Jacq.), a soja (Glycine max (L.) Merr.), o amendoim (Arachis hypogaea L.) e o algodão (Gossypium sp.) (Figura 1). Estas culturas além de servirem como matéria prima para a produção de biocombustíveis, também poderão contribuir para a recuperação de áreas degradas, visto que, no Brasil, cerca de 90 milhões de hectares se encontram em algum grau de degradação, e a maior parte dessas terras está no semiárido (Peres et al., 2005).

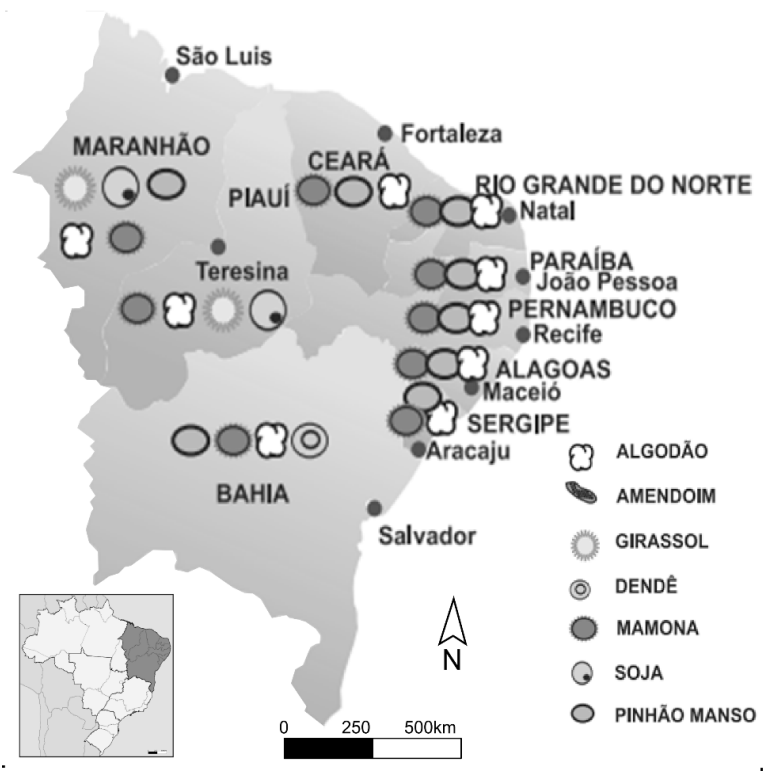

FIGURA 1 - Potencialidade para a produção de oleaginosas na Caatinga contemplando especificamente a região Nordeste do Brasil. FONTE: Adaptado de SEBRAE (2007).

As espécies vegetais do bioma Caatinga também apresentam potencial para a indústria de cosméticos e indústria de preservação de alimentos, por meio da extração de óleos essenciais (OEs), que neste tipo de vegetação constituem fontes 
potenciais de antioxidantes naturais (Hyldgaard et al., 2012). Essas substâncias são constituintes orgânicos voláteis responsáveis pelo aroma de muitas plantas. Podem ser obtidos de flores, folhas, frutos, sementes, gramas, raízes, rizomas e caules das plantas (Tisserand \& Balacs, 1999). Segundo Kim et al. (1995), alguns tem a capacidade de inibir bactérias de origem alimentar e prolongar a vida de prateleira de alimentos processados. Além disso, estudos apontam que essas substâncias possuem efeito antifúngico (Machado et al., 2013), anti-inflamatórios, antinociceptivo e antiespasmódico (Daniel et al., 2009; Adorjan \& Buchbauer, 2010; Pinho et al., 2012), atividades antitumoral (Wang et al., 2012; Quassinti et al., 2013) e inseticida (Lima et al., 2014). Portanto, é necessária a implantação de políticas públicas de conscientização, voltadas para o melhor manejo do extrativismo sustentável desse bioma, com vistas à preservação.

\section{Panorama político atual, impactos e considerações para o uso sustentável da biodiversidade da Caatinga}

Atualmente, cerca de 27 milhões de pessoas vivem na Caatinga, sendo a maioria carente e dependente dos recursos do bioma para sobreviver, o que ocasiona intensas alterações por atividades antrópicas, superando a fração de $51 \%$ em áreas degradadas (Alvarez \& Oliveira, 2013). Além de ser apontado como um dos mais críticos em termos de conservação da biodiversidade, este bioma também é considerado o mais insuficientemente estudado em termos da distribuição da sua cobertura atual, sobretudo no que se refere ao seu mapeamento (Dias et al., 2014). De fato, a Caatinga tem um imenso potencial para a conservação de serviços ambientais, uso sustentável e bioprospecção, que, se bem explorado, será decisivo para o desenvolvimento da região e do país (MMA, 2016).

Em entrevista à Agencia Brasil, o pesquisador Bergson Bezerra, do Instituto Nacional do Semiárido, ligado ao Ministério da Ciência, Tecnologia e Inovação, declarou que:

\begin{abstract}
"Construiu-se um preconceito em relação à Caatinga, sustentado na ideia de que ela representa um ambiente hostil e inóspito. As pessoas sempre acreditaram que ela não servia para nada, que era melhor retirar toda a Caatinga e substituí-la por vegetações frutíferas, por exemplo".
\end{abstract}

Entretanto, o referido pesquisador defende a ideia de que esse preconceito não temfundamentação e que a vegetação da Caatinga pode ser proporcionalmente mais eficiente que as florestas úmidas para absorver o gás carbônico presente na atmosfera. Ainda de acordo com Bezerra, a Caatinga é apontada como um dos biomas mais vulneráveis às mudanças climáticas associadas aos efeitos de aquecimento global e pela exploração pelo homem de forma desordenada e insustentável (Leitão, 2013).

Mata et al. (2015) reforçam as assertivas de Bezerra, indicando que, ao longo dos últimos anos, a vegetação da Caatinga vem sendo impactada por meio de variadas atividades antrópicas. Ainda segundo esses autores, um dos principais problemas a serem considerados acerca do uso da terra é as emissões de gases do efeito estufa que influenciam diretamente o balanço energético da atmosfera. Outrossim, observa-se que menos de $1 \%$ da Caatinga encontra-se protegida em áreas de conservação, sendo esse ecossistema considerado um dos 
menos protegidos do País. Em um levantamento realizado em 2007, a Embrapa apontou apenas 16 unidades de conservação federais e 7 estaduais que abrigam e protegem formações de Caatinga e áreas de "transição" entre a Caatinga e outros tipos de vegetação (Embrapa, 2007). Contudo, os sistemas de produção agrícolas, comumente praticados pela agricultura tradicional na região da Caatinga, caracterizaram-se, desde seus primórdios coloniais, por um extrativismo predatório (embora destinado à subsistência) dos recursos naturais de solo e de vegetação.

A atividade humana não sustentável como a agricultura-que converte remanescentes de vegetação em culturas de ciclo curto -, o corte de madeira para lenha, a caça de animais e a contínua remoção da vegetação para a criação de bovinos e caprinos tem levado ao empobrecimento ambiental, em larga escala, da Caatinga (Medeiros et al., 2000; Leal et al., 2003b; Leal et al. 2005). Todas as formas

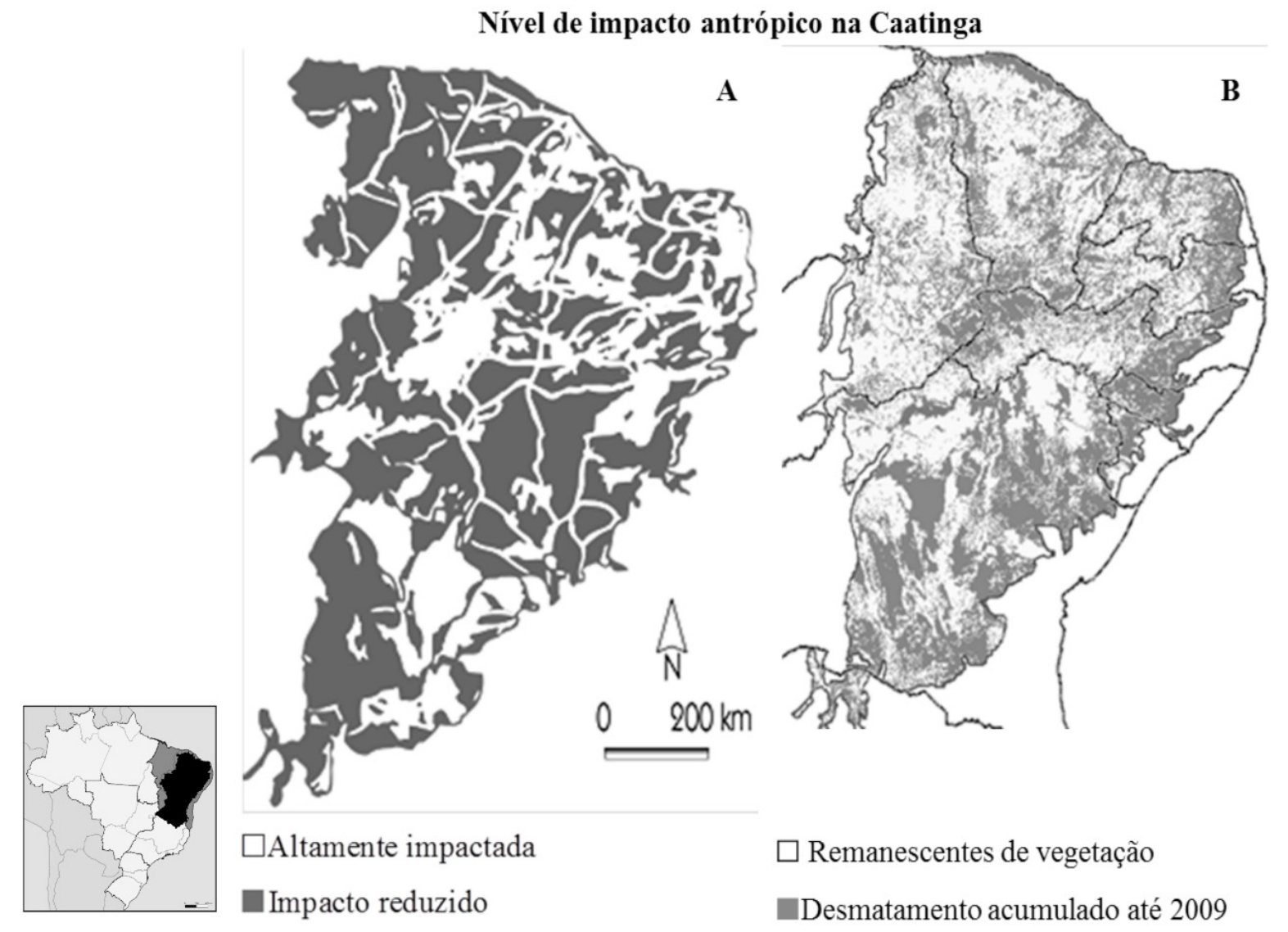

FIGURA 2 - Nível de impacto antrópico na Caatinga (A). As regiões em preto representam as “ilhas” formadas após retirar as áreas agrícolas e a "zona de impacto das estradas" a partir de modelo de largura: E = 10 km (Adaptado de Castelletti et al., 2004); Distribuição das áreas com remanescentes de vegetação e desmatamento acumulado até 2009 (B).

FONTE: Ibama (2009). 
e usos inapropriados do bioma têm causado sérios danos ambientais. O nível de impacto antrópico na Caatinga e áreas remanescentes de vegetação desse bioma pode ser observado na Figura 2 (A e $\mathrm{B}$, respectivamente). Observa-se na Figura 2A que as áreas que não foram influenciadas pelas atividades humanas formam um arquipélago, composto por "ilhas" de diferentes tamanhos, cercados por uma rede complexa de áreas alteradas (Leal et al., 2003a).

Estudos realizados pelo Instituto Brasileiro do Meio Ambiente e dos Recursos Naturais Renováveis (Ibama, 2009) sobre a distribuição dos remanescentes florestais e respectivos desmatamentos constataram que a área de remanescentes de vegetação da Caatinga é de 53,38\%. Assim, resta pouco mais da metade dos $826.411,23 \mathrm{Km}^{2}$ de floresta (Figura 2A). Esse problema foi abordado em maio de 2012, durante a conferência das Nações Unidas Rio+20, onde foi realizado a I Conferência Regional de Desenvolvimento Sustentável do Bioma Caatinga. Nessa ocasião, foi assinado por nove Estados do Nordeste e Minas Gerais a declaração da Caatinga. Neste documento ficou estabelecido 56 compromissos em prol do bioma, que deverão ser concretizados até o ano de 2020, tais como: aplicação de ações de enfrentamento à desertificação, já realizada com sucesso em outros espaços semiáridos; "produção de mudas e repovoamento de espécies nativas, utilizando as estruturas das instituições de ensino, pesquisa e extensão" com incentivos de remuneração, a exemplo da Bolsa Caatinga; "criação do pagamento por serviços ambientais voltados à proteção da Caatinga, em pequenas e médias propriedades (Bolsa Preservação)"; "delimitação de áreas experimentais para o desenvolvimento de pesquisas para recuperação de áreas degradadas" (Caatinga, 2012).

Como exposto, o extrativismo sustentável na Caatinga, baseado na preservação da diversidade genética e na valorização dos recursos naturais como solo, água e fauna, é particularmente crucial em regiões onde atividades agrícolas são comuns. Essa preocupação será condição indispensável para se prever o uso regular da terra pelos seus proprietários, bem como descobrir e desenvolver métodos não destrutivos de usos dos recursos florestais que sejam aplicáveis à região (Drumond et al., 2000).

Araújo Filho (2013) comenta que o ritmo de perda da vegetação primária alcança $2,7 \%$ ao ano, cerca de $80 \%$ da cobertura vegetal é secundária, com mais de $40 \%$ mantida em estágio pioneiro da sucessão secundária, e a desertificação já atinge em torno de $25 \%$ da área do território. Somado a isso a pressão demográfica em extensas áreas do domínio da Caatinga, o período de repouso da vegetação foi reduzido para menos de 10 anos. $\mathrm{O}$ autor ainda afirma que a riqueza florística forrageira da Caatinga é pouco conhecida, dificultando a seleção de espécies com potencial para utilização em sistemas agroflorestais ou como forrageiras. No caso da Caatinga, estima-se que o período mínimo adequado de pousio da vegetação seria, aproximadamente, entre 40 e 50 anos, tempo em que haveria uma sequência sucessional de 3 anos para a dominância das herbáceas, 17 anos para as arbustivas, 15 anos para um complexo arbustivo-arbóreo, quando, então, se verificaria a supremacia das árvores, a qual se completa após 10 anos, totalizando, portanto, cerca de 50 anos o tempo necessário para que a vegetação retorne ao clímax original. Todavia, esses valores podem variar bastante em função de fatores locais, flutuações climáticas e exaustão do banco natural de sementes, principalmente das arbóreas. Entretanto, 
em extensas áreas dos sertões nordestinos, o período de repouso efetivo está abaixo de 10 anos, ou seja, com plena dominância dos arbustos, não havendo tempo suficiente para a recuperação do solo e da vegetação, além de haver maior exposição à erosão, perda da biodiversidade florística e faunística, e queda dos índices de produção agrícola (Araújo Filho, 2013).

Em 2013, Araújo Filho estimou que a produção média anual de grãos obtida pelos sertanejos se situava em torno de $400 \mathrm{~kg} / \mathrm{ha}$. No entanto, pode-se obter em áreas de Caatinga plenamente recuperadas até $2.000 \mathrm{~kg} / \mathrm{ha} /$ ano, mesmo com as práticas da agricultura das queimadas. A proposta de um sistema de produção sustentável para regiões semiáridas deve levar em conta que, quase sempre, a pecuária pode representar para esta região uma exploração viável e, do ponto de vista ecológico, sobressai-se o fato de que o animal desempenha um papel importante na distribuição dos nutrientes, via esterco e urina, nas áreas do sistema de produção (Araújo Filho, 2013).

Em 2005, a elaboração do Zoneamento Ecológico Econômico (ZEE) do Nordeste, fundamentado nas dimensões econômicas, social, ambiental, tecnológica e institucional da sustentabilidade, contribuiu de forma efetiva para abordagens em diferentes recortes - como bacias, biomas, municipais e estaduais, proporcionando elementos para diferentes projetos em execução pelos governos federal, estaduais e locais (Moura, 2010). O ZEE é um importante subsídio para o planejamento de uma série de ações estratégicas como a definição de sistemas de produção e beneficiamento de produtos agroflorestais, criação e consolidação de Reservas Extrativistas e Florestas de Manejo Sustentável, definição de áreas críticas para a conservação do meio ambiente e da biodiversidade, dentre outras
(Moura, 2010).

Algumas outras iniciativas de extrativismo sustentável têm sido desenvolvidas ao longo de anos. Em Pernambuco, o Governo Estadual elaborou, no ano de 2004, o Plano Estratégico Ambiental de Pernambuco (Sectma, 2004), com o objetivo de promover a conservação e a recuperação do meio ambiente rural e urbano. O manejo sustentável da Caatinga estava previsto como Projeto 15 no Programa 5 - Produção Sustentável, visando "incentivar a utilização sustentável do bioma Caatinga, através da conservação da biodiversidade e da utilização de práticas sustentáveis". Neste projeto foram identificadas cerca de 67 espécies na Caatinga pernambucana, sendo 19 delas com potencial para uso na produção de óleos essenciais e ceras (Pareyn, 2010).

No Ceará a produção de óleos essenciais a partir da vegetação nordestina também tem sido alvo de intensas pesquisas desde 1973 com a criação do Departamento de Química Orgânica e Inorgânica da Universidade Federal do Ceará. A equipe do Prof. Afrânio Fernandes percorreu mais de 40.000 km e coletou mais de 4.000 amostras em praticamente todos os municípios do Nordeste com o objetivo de formar um banco de informações sobre plantas aromáticas e medicinais. A partir dessas pesquisas, foram publicados vários livros, foram desenvolvidos extratores de óleos e registrou-se três patentes de óleos essenciais do Nordeste (Craveiro, 2012).

De acordo com Araújo Filho (2013) há três estratégias para a conservação que podem, quando seguidas, facilitar a sustentabilidade das tecnologias de manipulação da Caatinga: preservação de até 400 árvores por hectare, ou o equivalente a $40 \%$ de cobertura arbórea; utilização máxima de $60 \%$ da forragem disponível e preservação da mata 
ciliar em toda a malha de drenagem da pastagem. A manutenção de uma cobertura arbórea em áreas de Caatinga manipulada serve a cinco propósitos: preservação da biodiversidade da vegetação nativa; interceptação de porção significativa da precipitação pluvial, contribuindo para o controle da erosão do solo e das enxurradas; aporte de matéria orgânica para a manutenção de fertilidade do solo; produção de forragem e conforto térmico. A preservação da mata ciliar visa a proteção dos recursos hídricos pelo controle da quantidade e da qualidade da água que se escoa na malha de drenagem da pastagem, evitando o assoreamento dos mananciais e nascentes, além de servir como um corredor ecológico e abrigo para a fauna.

A Embrapa (2007) também sugere estratégias que podem minimizar os impactos negativos que foram e vem sendo causados neste bioma, como por exemplo: aumento do número de unidades de conservação; incentivos fiscais para a preservação; realização de campanhas de conscientização ambiental, principalmente nas comunidades próximas às áreas de preservação; melhoria na fiscalização das áreas; diversificação de culturas, incentivando a prática de uso de sistemas agroflorestais; práticas de agricultura sustentável.

Mesmo com tantas recomendações para o desenvolvimento sustentável do bioma, a utilização da Caatinga tem sido intensiva e desordenada, não havendo prática de reposição florestal. Além da produção para fins energéticos, esse complexo sistema produtivo deveria ser encarado como uma atividade de preservação da biodiversidade, valorizando o seu potencial de suporte social, econômico e ambiental. O manejo sustentável da vegetação do Nordeste é, por assim dizer, uma perspectiva viável para o desenvolvimento regional e a inclusão do componente florestal pode garantir a produção de madeira, carvão, forragem, frutos, fibras, óleos extrativos e medicinais, de forma eficiente e equilibrada (Alvarez \& Oliveira, 2013).

Nesse contexto, entende-se que, junto à necessidade de preservação, faz-se necessário programar uma agenda de conservação - e essa será uma tarefa especialmente difícil, considerando a densidade populacional, o grau de alteração dos habitats remanescentes e a longa história de pobreza e seca. Investimentos em pesquisas na Caatinga podem ampliar e difundir o conhecimento necessário para o desenvolvimento sustentável do bioma e, desta forma, poder-se-á definir ações para seu aproveitamento econômico, por meio de tecnologias e métodos apropriados, sem agressão às relações naturais do ambiente e que visem preservá-la da ameaça de extinção. Consequentemente a partir da utilização sustentável dos recursos naturais e do manejo adequado da sua biodiversidade poder-se-á impulsionar o desenvolvimento de toda a região (Loiola et al., 2012).

\section{Considerações finais}

O desenvolvimento sustentável é aquele que atende às necessidades do presente sem comprometer as gerações futuras, assim, quando se fala em desenvolvimento sustentável da Caatinga, pretende-se que sua exploração contribua para o desenvolvimento econômico e social da região Nordeste no momento, sem comprometer a renovabilidade.

Nesta perspectiva é necessário aumentar as Unidades de Conservação desse bioma e adotar técnicas extrativistas sustentáveis de seus recursos naturais, de forma anão comprometer a biodi- 
versidade. Sendo assim, o manejo sustentável da Caatinga é uma possibilidade real, tecnicamente comprovada. Porém, sabe-se que a promoção da conservação e do uso sustentável dos recursos naturais não é uma tarefa fácil, e só será possível através de um intenso processo de conscientização e capacitação de todos os atores envolvidos por meio da formulação de políticas públicas que priorizem a realidade ambiental e socioeconômica do bioma, da geração, sistematização e disseminação de informações, da construção de uma matriz de incentivos adaptados à realidade local, e do fortalecimento institucional, como forma de garantir a sobrevivência do ecossistema.

\section{Referências}

Adorjan, B.; Buchbauer, G. Biological properties of essential oils: an updated review. Flavour and Fragrance Journal, 25, 407-426, 2010. doi: 10.1002/ffj.2024

Alvarez, I. A.; Oliveira, A. R. Portal Dia de Campo. Artigos especiais. Manejo da Caatinga é essencial ao desenvolvimento do Semiárido, 2013. Disponível em: <http:// www.diadecampo.com.br/zpublisher/materias/Newsletter. asp id $=27746 \&$ secao $=$ Artigos $\% 20$ Especiais $>$. Acesso em: 07 fev. 2016.

Araújo Filho, J. A. Manejo pastoril sustentável da caatinga . $1^{\mathrm{a}}$ ed. Recife: Projeto Dom Helder Camara, 2013.

Bezerra, J. M.; Moura, G. B. A.; Silva, B. B.; Lopes, P. M. O.; Silva, E. F. F. Parâmetros biofísicos obtidos por sensoriamento remoto em região semiárida do estado do Rio Grande do Norte, Brasil. Revista Brasileira de Engenharia Agricola e Ambiental, 18 (1), 73-84, 2014. doi: 10.1590/ S1415-43662014000100010

MMA - Ministério do Meio Ambiente. Biomas: Caatinga. Disponível em $<$ http://www.mma.gov.br/biomas/caatinga $>$. Acesso em: 08 fev. 2016.

Caatinga. Rio+20. I Conferência Regional de Desenvolvi- mento Sustentável do Bioma Caatinga. Declaração da $\mathrm{Ca}$ atinga, 2012. Disponível em: $<\mathrm{http}: / / \mathrm{www}$.meioambiente. mg.gov.br/images/stories/newsletter/cartadacaatinga-rio20. pdf > . Acesso em: 07 out. 2012.

Calixto Júnior, J. T.; Drumond, M. A. Estudo comparativo da estrutura fitossociológica de dois fragmentos de Caatinga em níveis diferentes de conservação. Pesquisa Florestal Brasileira, 34(80), 345-355, 2014. doi: 10.4336/2014. pfb.34.80.670

Castelletti, C. H. M.; Silva, J. M. C.; Tabarelli, M.; Santos, A. M. M. Quanto ainda resta da Caatinga? Uma estimativa preliminar. In: Silva J. M. C.; Tabarelli, M.; Fonseca, M. T.; Lins, L. V. Biodiversidade da Caatinga: áreas e ações prioritárias para a conservação. Brasília: Ministério do Meio Ambiente, p. 92-100, 2004.

Craveiro A. A. Parque de Desenvolvimento Tecnológico Campus do Pici-UFC. Do laboratório ao Mercado: 34 anos de P\&D em óleos essenciais no Nordeste, 2012. Disponível em: $<$ http://www.ivsboe.padetec.ufc.br/palestras/afranio. pdf $>$. Acesso em: 07 out. 2012.

Daniel, N. A.; Sartoretto, S. M.; Schmidt, G.; Caparroz-Assef, S. M.; Bersani-Amado, C. A.; Cuman, R. K. N. Anti-inflammatory and antinociceptive activities of eugenol essential oil in experimental animal models. Revista Brasileira de Farmacognosia, 19, 212-217, 2009. doi: 10.1590/ S0102-695X2009000200006.

Dias, P. M. S.; Diodato, M. A.; Grigio, A. M. Levantamento fitossociológico de remanescentes florestais no município de Mossoró - RN. Revista Caatinga, 27(4), 183-190, 2014.

Drumond, M. A.; Kiill, L. H. P.; Lima, P. C. F.; Oliveira, M. C.; Oliveira, V. R.; Albuquerque, S. G.; Nascimento, C. E. S.; Cavalcanti, J. Estratégias para o uso sustentável da biodiversidade da caatinga. In: Anais...Seminário para avaliação e identificação de ações prioritárias para a conservação, utilização sustentável e repartição de beneficios da biodiversidade do bioma Caatinga. Petrolina, 31 de ago., 2000.

Embrapa - Empresa Brasileira de Pesquisa Agropecuária. Preservação e uso da Caatinga, 2007. Disponível em: <https://ainfo.cnptia.embrapa.br/digital/bitstream/ item/11949/2/00081410.pdf>. Acesso em: 15 de out. 2012.

Gamarra-Rojas, C. F. L.; Sampaio, E. V. S. B. Espécies de 
Caatinga no banco de dados do CNIP. In: Sampaio, E. V. S. B.; Giulietti A. M.; Virgínio, J.; Gamarra-Rojas, C. F. L. Vegetação e flora da Caatinga. Recife: APNE-CNIP, p. 91-1012002.

Giulietti, A. M.; Bocage Neta, A. L.; Castro, A. A. J. F.; Gamarra-Rojas, C. F. L.; Sampaio, E. V. S. B.; Virgínio, J. F.; Queiroz, L. P.; Figueiredo, M. A.; Rodal, M. J. N.; Barbosa, M. R. V.; Harley, R. M. Diagnóstico da vegetação nativa do bioma Caatinga. Brasília: Ministério do Meio Ambiente, 2010.

Giulietti, A. M.; Bocage Neta, A. L.; Castro, A. A. J. F.; Gamarra-Rojas, C. F. L.; Sampaio, E. V. S. B.; Virgínio, J. F.; Queiroz, L. P.; Figueiredo, M. A.; Rodal, M. J. N.; Barbosa, M. R. V.; Harley, R. M. Diagnóstico da vegetação nativa do bioma Caatinga. In: Silva, J. M. C.; Tabarelli, M.; Fonseca, M. T.; Lins, L. V. (Orgs.). Biodiversidade da Caatinga: áreas e ações prioritárias para a conservação. Brasília: Ministério do Meio Ambiente, p. 47-90, 2004.

Guimarães Filho, C.. Um agronegócio para a Caatinga, 2012. Disponível em: <http://www.fundaj.gov.br/index. php?option $=$ com_content\&view $=$ article $\& i d=1895 \% 3$ Aum-agronegocio-para-a-caatinga- $\&$ catid $=58 \% 3$ Aobservanordeste\&Itemid=414>. Acesso em: 10 out. 2012.

Hyldgaard, M.; Mygind, T.; Meyer, R. L. Essential oils in food preservation: mode of action, synergies, and interactions with food matrix components. Frontiers in Microbiology, 3, 1-24, 2012. doi: 10.3389/FMICB.2012.00012

Ibama - Instituto Brasileiro do Meio Ambiente e dos Recursos Naturais Renováveis. Monitoramento do desmatamento nos biomas brasileiros por satélite acordo de cooperação técnica MMA/IBAMA monitoramento do bioma Caatinga, 2009. Disponível em: <http://www.mma.gov.br/estruturas/ sbf_chm_rbbio/_arquivos/relatoriofinal_cerrado_2010_final_72_1.pdf $>$. Acessoem: 15 de mai. 2015.

Kim, J. M.; Marshall, S. R.; Cornell, J. A.; Preston, J. F.; Wei, C. I. Antibacterial activity of carvacrol, citral, and geraniol against Salmonella typhimurium in culture medium and on fish cubes. Journal of Food Science, 60, 1364-8, 1995. doi: 10.1111/j.1365-2621.1995.tb04592.x

Leal, I. R.; Silva, J. M. C. da; Tabarelli, M.; Lacher-Jr., T. E. Mudando o curso da conservação da biodiversidade na
Caatinga do Nordeste do Brasil. Megadiversidade, 1(1), 139-146, 2005.

Leal, I. R.; Tabarelli, M.; Silva, J. M. C. Ecologia e Conservação da Caatinga. Recife: Editora Universitária: Universidade Federal de Pernambuco, 2003a.

Leal, I. R.; Vicente, A.; Tabarelli, M. Herbivoria por caprinos na Caatinga: uma estimativa preliminar. In: Leal, I. R.; Tabarelli, M.; Silva, J. M. C. (Eds.). Ecologia e Conservação da Caatinga. Recife: Editora Universitária: Universidade Federal de Pernambuco, p. 695-715, 2003b.

Leitão, T. Caatinga pode ser mais eficiente do que florestas tropicais na absorção de gás carbônico, 2013. Disponível em<http://www.ebc.com.br/noticias/brasil/2013/04/caatinga-pode-ser-mais-eficiente-do-que-florestas-tropicais-na-absorcao-de >. Acesso em: 02 fev. 2016.

Lima, R. K.; Cardoso, M. G.; Moraes, J. C.; Carvalho, S. M.; Melo, B. A.; Vieira, S. S. Composição química e toxicidade de óleos essenciais para o pulgão-verde Schizaphisgraminum (Rondani, 1852). Arquivos do Instituto Biológico, 81 (1), 22-29, 2014. doi: 10.1590/S1808-16572014000100005

Loiola, M. I. B.; Roque, A. A.; Oliveira, A. C. P. Caatinga: Vegetação do semiárido brasileiro. RevistaEcologi@,4, 14-19, 2012. Disponível em: http://speco.fc.ul.pt/revistaecologia_4_art_8_1.pdf

Machado, R. M. A.; Mussi-Dias, V.; Souza, C. L. M.; Silva, L. B.; Freire M. G. M. Avaliação de óleos essenciais sobre o crescimento in vitro do fungo Colletotrichum gloeosporioides. Revista Biologia e Saúde, 8(3), 64-75, 2013.

Mata, M. V. M.; Hoelzemann, J. J.; Sousa Neto, E. R.; Aguiar, A. P. D.; Vieira, R. M. S. P.; Assis, T.; Ometto, J. P. Emissões de $\mathrm{CO}_{2}$ Provenientes do Uso e Mudanças no Uso da Terra no Bioma Caatinga no Nordeste Brasileiro. Revista Brasileira de Geografia Física, 8(1), 144-155, 2015. Disponível em: http://www.revista.ufpe.br/rbgfe/index.php/ revista/article/viewFile/1171/766

Marinho, M. G. V.; Silva, C. C.; Andrade, L. H. C. Levantamento etnobotânico de plantas medicinais em área de Caatinga no município de São José de Espinharas, Paraíba, Brasil. Revista Brasileira de Plantas Medicinais, 13(2), 170-182, 2011. doi: 10.1590/S1516-05722011000200008 
Medeiros, L. P.; Girão, R. N.; Girão, E. S.; Leal, J. A. Caprinos. Teresina: Empresa Brasileira de Pesquisa Agropecuária, 2000.

Moraes, D. In vivo. FIOCRUZ. Bioma Caatinga, 2016. Disponível em: <http://www.invivo.fiocruz.br/cgi/cgilua.exe/ sys/start.htm?infoid=962\&sid=2>. Acesso em: 29 fev. 2016.

Moura, A. S. S. Reserva da biosfera da Caatinga. In: Gariglio, M. A.; Sampaio, E. V. S. B.; Cestaro, L. A.; Kageyama, P. Y. Uso sustentável e conservação dos recursos Florestais da Caatinga. Brasilia: Serviço Florestal Brasileiro, 2010.

Newman, D. J.; Cragg, G. M. Natural Products As Sources of New Drugs over the 30 Years from 1981 to 2012. Journal of Natural Products, 75, 311-35, 2012. doi: 10.1021/ np200906s

Pareyn, F. G. C. A importância da produção não madeireira na Caatinga. In: Gariglio, M. A.; Sampaio, E. V. S. B.; Cestaro, L. A.; Kageyama, P. Y. (Orgs.). Uso sustentável e conservação dos recursos Florestais da Caatinga. Brasília: Serviço Florestal Brasileiro, 2010.

Paupitz, J. Elementos da estrutura fundiária e uso da terra no Semiárido Brasileiro. In: Gariglio, M. A.; Sampaio, E. V. S. B.; Cestaro, L. A.; Kageyama, P. Y. (Orgs.). Uso sustentável e conservação dos recursos florestais da Caatinga. Brasília: Serviço Florestal Brasileiro, 2010.

Peres, J. R. R.; Freitas Junior, E.; Gazzoni, D. L. Biocombustíveis: uma oportunidade para o agronegócio brasileiro. Revista de Politica Agrícola, 14(5), 31-42, 2005. Disponível em: https://seer.sede.embrapa.br/index.php/RPA/article/ view/528/478

Pinho, J. P.; Silva, A. S.; Pinheiro, B. G.; Sombra, I.; Bayma, J. C.; Lahlou, S.; Sousa, P. J.; Magalhães, P. J. Antinociceptive and antispasmodic effects of the essential oil of Ocimum micranthum: potential anti-inflammatory properties. Revista Planta Medica, 78, 681-685, 2012. doi: 10.1055/s-0031-1298372

Prado, D. As Caatingas da América do Sul. In: Leal, I. R.; Tabarelli, M.; Silva, J. M. C. (Eds.). Ecologia e conservação da Caatinga. Recife: Editora Universitária: Universidade Federal de Pernambuco, 2003.

Quassinti, L.; Bramucci, M.; Lupidi, G.; Barboni, L.; Ric- ciutelli, M.; Sagratini, G.; Papa, F.; Capriolo, G. Petrelli, D.; Vitali, L. A.; Vittori, S.; Maggi, F. In vitro biological activity of essential oils and isolated furano sesquiterpenes from the neglected vegetable Smyrnium olusatrum L. (Apiaceae). Food Chemistry, 138, 808-813, 2013. doi: 10.1016/j. foodchem.2012.11.075

Queiroz, M. A. Recursos Genéticos Vegetais da Caatinga para o Desenvolvimento do Semiárido Brasileiro. Revista Brasileira de Geografia Física, 6, 1135-1150, 2011. Disponível em: http://www.revista.ufpe.br/rbgfe/index.php/ revista/article/view/273/223

Sampaio, E. V. S. B.; Pareyn, F. G. C.; Figueirôa, J. M.; Santos Junior, A. G. Espécies do Semiárido baiano com potencial econômico. Magistra, 18, 6-8, 2006. Disponível em: http://www.revista.ufpe.br/rbgfe/index.php/revista/ article/view/273/223

Sampaio, E. V. S. B.; Giulietti, A.M.; Virgínio, J.; Gamarra-Rojas, C.F.L. Vegetação e flora da Caatinga. Recife: Associação Plantas do Nordeste e Centro Nordestino de Informação sobre Plantas, 2002.

SEBRAE - Serviço Brasileiro de Apoio ás Micro e Pequenas Empresas. Biodisel, 2007. Disponível em: <http://201.2.114.147/bds/bds.nsf/D170D324C7521915832572B200470F63/\$File/NT00035116. pdf $>$. Acesso em: 10 jun. 2015.

SECTMA - Secretaria de Ciência, Tecnologia e Meio Ambiente. Cenários para o bioma Caatinga. Recife: Gráfica e Editora Liceu, 2004.

Silva, A. C. C.; Prata, A. P. N.; Souto, L. S.; Mello, A. A. Aspectos de ecologia de paisagem e ameaças à biodiversidade em uma unidade de conservação na Caatinga, em Sergipe. Revista Árvore, 37(3), 479-490, 2013. doi: 10.1590/ S0100-67622013000300011

Silva, J. M. C.; Tabarelli, M.; Fonseca, M. T.; Lins, V. (Orgs.). Biodiversidade da Caatinga: áreas e ações prioritárias para a conservação. Brasília: Ministério do Meio Ambiente, 2004.

Silva, T. S.; Freire, E. M. X. Abordagem etnobotânica sobre plantas medicinais citadas por populações do entorno de uma unidade de conservação da Caatinga do Rio Grande do Norte, Brasil. Revista Brasileira de Plantas 
Medicinais, 12(4), 427-435, 2010. doi: 10.1590/S151605722010000400005

Tabarelli, M.; Vicente, A. Conhecimento sobre plantas lenhosas da Caatinga: lacunas geográficas e ecológicas. In: Silva, J. M. C.; Tabarelli, M.; Fonseca, M. T.; Lins, V. (Orgs.). Biodiversidade da Caatinga: áreas e ações prioritárias para a conservação. Brasília: Ministério do Meio Ambiente, 2004.

Tisserand, R.; Balacs, T. Essential Oil Safety: A Guide for Health Care Professionals. London: Churchill Livingstone; 1999.

UNESCO - United Nations Educational, Scientific and Cultural Organization. Biodiversidade, 2012. Disponível em: $<$ http://www.biosferadacaatinga.org.br/biodiversidade. html>. Acesso em: 10 out. 2012.
Viana, D. L. Avaliação dos impactos ocasionados pela atividade de pedreira no complexo Aluízio Campos. Revista Brasileira de Informações Científicas, 2(2), 45-48, 2011. Disponível em: http://www.rbic.com.br/artigos\%20pdf/ vol2_n2\%20-\%202011/4\%20vol2\%20n2.pdf

Wang, W.; Li, N.; Luo, H.; Zu, Y.; Efferth, T. Antibacterial Activity and Anticancer Activity of Rosmarinus officinalis L. Essential Oil Compared to That of Its Main Components. Molecules, 17, 2704-2713, 2012. doi: 10,3390/molecules 17032704 